\title{
DA APLICAÇÃO DOS DIREITOS HUMANOS NOS PROCEDIMENTOS DE INVESTIGAÇÃO INTERNA E SUAS CONSEQUENCIAS NO PROCESSO CRIME
}

\author{
THE APPLICATION OF HUMAN RIGHTS IN THE INTERNAL INVESTIGATION \\ PROCEEDINGS AND ITS CONSEQUENCES IN CRIMINAL TRIALS
}

\author{
Irene Portella ${ }^{12}$ \\ Henrique Ribeiro Cardoso ${ }^{2}$ \\ Rodrigo Campos Hasson Sayeg ${ }^{3}$
}

\begin{abstract}
Resumo
O direito brasileiro aos poucos vem introduzindo novos mecanismos de Governança Interna para facilitar os processos investigativos do Estado em face de crimes praticados dentro de estruturas corporativas, chegando até o ponto de se falar em uma transferência da função investigativa do Estado para o Particular. Ocorre que, dentro desse espectro, em se tratando de uma função investigativa, essa é acompanhada de certos direitos e garantias constitucionais, as quais o Estado deve respeitar, sob pena desta investigação se tornar nula e inutilizável. Dessa forma esse artigo visa enfrentar a questão que emerge com essa transferência, se os direitos e garantias constitucionais dos acusados são aplicáveis dentro dos processos de investigação interna de Governança Coorporativa
\end{abstract}

Palavras-Chave: Compliance, Governança, direitos e garantias fundamentais, processo penal

\footnotetext{
${ }^{1}$ Doutora em Direito Constitucional pelo departamento de Direito Público e Teoria do Estado, pela Universidade de Santiago de Compostela.

2 Promotor de Justiça em Sergipe desde agosto de 1997, titular da Primeira Curadoria da Fazenda Pública de Aracaju desde 2002. Também foi Advogado e Defensor Público na Bahia, tendo sido ainda nomeado, mediante aprovação em concurso público, para o cargo de Procurador da Fazenda do Estado da Bahia. No campo acadêmico, é Doutor em Direito, Estado e Cidadania (UGF/Rio), com Pós-doutorado em Democracia e Direitos Humanos (IGC - Universidade de Coimbra) e Pós-doutorado em Direitos Humanos e Desenvolvimento (PPGCJ/UFPB); Mestre em Direito, Estado e Cidadania (UGF/Rio); Especialista em Direito Constitucional Processual (FAPESE/UFS); Graduado em Direito pela Universidade Estadual de Santa Cruz (UESC/Bahia); Professor do Programa de Pós-graduação da Universidade Federal de Sergipe (Mestrado/PRODIR/UFS); Professor de Programa de Pós-graduação da Universidade Tiradentes (Mestrado/PPGD/UNIT); Professor da Escola Superior do Ministério Público de Sergipe (ESMP/SE).

${ }^{3}$ Rodrigo Sayeg é Advogado, Mestre em Direito Americano pela California Western School of Law e Doutorando em Direito Empresarial pela Unicuritiba.
} 


\begin{abstract}
It has been a recent trend in Brazilian law the introduction of new mechanisms of internal governance and compliance with the goal of facilitating the investigations of crimes occurring inside complex corporate structures, coming to the point of a transference of the investigative function of the State to private companies. However, this transference is accompanied by the question of the constitutional guarantees that are intrinsical to the criminal investigation which, if disrespected, can make these null and unusable by law enforcement branches. Therefore, this paper will try to face the question of the application of these guarantees in the internal investigation proceedings.
\end{abstract}

Key-Words: Compliance, governance, fundamental rights and guarantees, criminal procedure law.

\title{
1 INTRODUÇÃO
}

Nas últimas décadas, com o desenvolvimento da tecnologia e estabelecimento de novos meios de comunicação, a economia global rompeu barreiras territoriais possibilitando a realização de transações comerciais de forma quase que ilimitada. Esse panorama denota o surgimento de novas condutas, as quais são reputadas dignas de tutela penal pelo legislador, sendo alçadas, assim, à categoria de bens jurídicos penais.

Conforme afirma Julio Cezar Faria Zini:

O Direito Penal Econômico adquire notável importância em nossa sociedade pluralista, globalizada e que abarca relações econômicas complexas, internacionalizadas e com participantes cada vez mais difusos ${ }^{3}$.

Em paralelo, surgem novas maneiras de cometimento de condutas já criminalizadas, atraindo a atenção do legislador para a necessidade de intensificação na prevenção e repressão dessas modalidades criminosas preexistentes.

\footnotetext{
3 ZINI, Júlio César Faria. APONTAMENTOS SOBRE O DIREITO PENAL ECONÔMICO E SUAS ESPECIFICIDADES, Rev. Fac. Direito UFMG, Belo Horizonte, n. 60, p. 147 a 207, jan./jun. 2012. Disponível em $\quad<$ https://www.direito.ufmg.br/revista/index.php/revista/article/download/P.0304-2340.2012v60p147/165> extraído em 22.01.2020
} 
Esse contexto enseja a edição de novas leis, com o estabelecimento de novos e mais complexos tipos penais, criados com o intuito de tentar acompanhar as mudanças econômicas. Nesse cenário, o próprio Estado reconhece sua falibilidade no que diz com a eficaz prevenção e repressão dessas condutas modernas ${ }^{4}$.

A partir daí surge o que se denomina de compliance. De forma sintética, pode-se afirmar que esse movimento acaba por transferir, em alguma medida, as incumbências essencialmente estatais de investigação de condutas contrárias ao ordenamento jurídico para a iniciativa privada.

\section{O QUE É O COMPLIANCE}

O compliance, vem do termo inglês "to comply", basicamente significa respeitar e cumprir a legislação.

Conforme afirma Guhan Subramanian, o estudo de governança corporativa pode ser remontado desde os anos 30, porém este realmente tomou forma nos anos $70^{5}$.

Conforme define a Comissão de Valores Mobiliários, governança corporativa é o conjunto de práticas que tem por finalidade otimizar o desempenho de uma companhia ao proteger todas as partes interessadas, tais como investidores, empregados e credores, facilitando o acesso ao capital ${ }^{6}$.

Por sua vez, afirmam José Alberto Monteiro Martins e Fernando Gustavo Knoerr acerca da importância do compliance:

O compliance é a evidência da autorregulação conferida pelo Estado às empresas, para que o poder de polícia seja exercido internamente nas empresas, por elas mesmas,

\footnotetext{
${ }^{4}$ BERTONI, Felipe Faoro, Compliance e a privatização da investigação criminal. Canal Ciências Criminais. 17.11.2015. Disponível em $<$ https://canalcienciascriminais.com.br/compliance-e-a-privatizacao-da-investigacaocriminal/> extraído em 22.01.2020

${ }^{5}$ SUBRAMANIAN, Guhan. Corporate Governance 2.0. Havard Business Review. 2015. Disponível em $<$ https://hbr.org/2015/03/corporate-governance-2-0>. Acesso em 22.01.2020. Texto original: Although corporate governance is a hot topic in boardrooms today, it is a relatively new field of study. Its roots can be traced back to the seminal work of Adolf Berle and Gardiner Means in the 1930s, but the field as we now know it emerged only in the 1970s.

${ }^{6}$ CVM Recomendações Da CVM Sobre Governança Corporativa. Disponível em

$<$ http://www.cvm.gov.br/export/sites/cvm/decisoes/anexos/0001/3935.pdf $>$ acesso em 23.01.2020
} 
através de programas de compliance contendo código de conduta e ética e políticas internas, com o objetivo de disseminar a boa conduta e ética nos negócios e coibir atos de corrupção ${ }^{7}$.

Assim, nunca se exigiu tanto das organizações uma conduta ética, transparente e responsável como na atualidade e é cada vez mais amplamente aceito que a ausência de uma política corporativa de compliance e a falta de integridade tornaram-se um problema mundial com a quantidade de escândalos, noticiada nos últimos anos, de corrupção e fraude envolvendo o relacionamento de organizações privadas com o Poder Público.

Como exemplos em uma escala global, tivemos os escândalos que permitiram a crise econômica de 2008 que impulsionaram uma reforma nos sistemas regulatórios do sistema financeiro norte americano ${ }^{8}$.

No Brasil, tivemos a investigação e operação Lava Jato, na qual um esquema de corrupção empresarial tomou proporções enormes ao ponto de ser relatado pela revista Época, que, conforme relatório emitido pela Polícia Federal, foram movimentados mais de $\mathrm{R} \$ 12$ Trilhões de Reais ${ }^{9}$, valor equivalente ao PIB brasileiro em 2018, envolvendo as maiores empresas nacionais e inúmeras figuras políticas.

Assim, em resposta a essa nova forma de pratica de crimes, os quais podem tomar proporções enormes, o Brasil visou introduzir o termo complience na legislação Brasileira através da Lei $\mathrm{n}^{\mathrm{o}}$ 12.846/13, denominada Lei Anti-Corrupção, a qual dispõe sobre a responsabilização civil e administrativa de pessoas jurídicas pela pratica de atos contra a administração pública.

Nessa Lei, é estabelecido, como incentivo a instalação de políticas de compliance, que caso a empresa possua "mecanismos e procedimentos internos de integridade, auditoria e

\footnotetext{
7 MARTINS, José Alberto Monteiro e KNOERR Fernando Gustavo, THE POLICE POWER AND COMPLIANCE IN A LEGAL STATE AND THEIR INFLUENCE ON THE ANTI-CORRUPTION LAW (LAW 12,846 DATED AUGUST 1, 2013). Revista Jurídica Unicuritiba vol. 02, n . 43, Curitiba, 2016. pp.351-387 DOI: $10.6084 / \mathrm{m} 9$. figshare.3383485. Disponível

em $<$ http://revista.unicuritiba.edu.br/index.php/RevJur/article/view/1836/1211> acesso em 25.01.2020.

${ }^{8}$ GUYNN Randall D. The Financial Panic of 2008 and Financial Regulatory Reform. Harvard Law School Forum on Corporate Governance. Disponível em <https://corpgov.law.harvard.edu/2010/11/20/the-financial-panic-of2008-and-financial-regulatory-reform/> acesso em 22.01.2020

${ }^{9}$ POLICÍA FEDERAL DO BRASIL. Operação Lava Jato Números. Disponível em

$<$ http://www.pf.gov.br/imprensa/lava-jato/numeros-da-operacao-lava-jato $>$ acesso em 19.12.2020
} 
incentivo à denúncia de irregularidades e a aplicação efetiva de códigos de ética e de conduta no âmbito da pessoa jurídica", isto é setor de compliance, será possível uma atenuação na aplicação da pena:

Art. 7o Serão levados em consideração na aplicação das sanções: [...]VIII - a existência de mecanismos e procedimentos internos de integridade, auditoria e incentivo à denúncia de irregularidades e a aplicação efetiva de códigos de ética e de conduta no âmbito da pessoa jurídica; ${ }^{10}$

Essa Lei vem seguindo o exemplo internacional, como por exemplo, a legislação do Reino Unido, denominada Bribery Act 2010, que consagra a aplicação do instituto da failure of comercial organizations to prevent bribery (falha em prevenir o suborno), dispensando a necessidade de se avaliar necessariamente os aspectos subjetivos da conduta para fins de responsabilização de pessoas jurídicas ${ }^{11}$.

Estes mecanismos de governança corporativa interna foram regulados pelo Decreto $8.420 / 15^{12}$. O referido diploma legal define essa estrutura como "Programa de Integridade", como se vê no artigo 41:

\section{DO PROGRAMA DE INTEGRIDADE}

Art. 41. Para fins do disposto neste Decreto, programa de integridade consiste, no âmbito de uma pessoa jurídica, no conjunto de mecanismos e procedimentos internos de integridade, auditoria e incentivo à denúncia de irregularidades e na aplicação efetiva de códigos de ética e de conduta, políticas e diretrizes com objetivo de detectar e sanar desvios, fraudes, irregularidades e atos ilícitos praticados contra a administração pública, nacional ou estrangeira.

\footnotetext{
${ }^{10}$ BRASIL. Lei ${ }^{\circ} 12.846$, de $1^{\circ}$ de agosto de 2013. Dispõe sobre a responsabilização administrativa e civil de pessoas jurídicas pela prática de atos contra a administração pública, nacional ou estrangeira, e dá outras providências. Disponível em <http://www.planalto.gov.br/ccivil_03/_Ato2011-2014/2013/Lei/L12846.htm>

${ }^{11}$ REINO UNIDO. Bribery Act. 2010. Disponível em <http://www.legislation.gov.uk/ukpga/2010/23/contents> acesso em 24.01.2020.

${ }^{12}$ BRASIL. Decreto $n^{\circ} 8.420$, de 18 de março de 2015.

Regulamenta a Lei $\mathrm{n}^{\circ} 12.846$, de $1^{\circ}$ de agosto de 2013 , que dispõe sobre a responsabilização administrativa de pessoas jurídicas pela prática de atos contra a administração pública, nacional ou estrangeira e dá outras providências. Disponível em <http://www.planalto.gov.br/ccivil_03/_Ato2015-2018/2015/Decreto/D8420.htm> acesso em 25.01.2020.
} 
Parágrafo Único. O programa de integridade deve ser estruturado, aplicado e atualizado de acordo com as características e riscos atuais das atividades de cada pessoa jurídica, a qual por sua vez deve garantir o constante aprimoramento e adaptação do referido programa, visando garantir sua efetividade.

\section{Por sua vez o artigo $42^{13}$ trás todos os requisitos mínimos a serem analisados e} considerados nos programas de integridade:

I - comprometimento da alta direção da pessoa jurídica, incluídos os conselhos, evidenciado pelo apoio visível e inequívoco ao programa;

II - padrões de conduta, código de ética, políticas e procedimentos de integridade, aplicáveis a todos os empregados e administradores, independentemente de cargo ou função exercidos;

III - padrões de conduta, código de ética e políticas de integridade estendidas, quando necessário, a terceiros, tais como, fornecedores, prestadores de serviço, agentes intermediários e associados;

IV - treinamentos periódicos sobre o programa de integridade;

V - análise periódica de riscos para realizar adaptações necessárias ao programa de integridade;

VI - registros contábeis que reflitam de forma completa e precisa as transações da pessoa jurídica;

VII - controles internos que assegurem a pronta elaboração e confiabilidade de relatórios e demonstrações financeiros da pessoa jurídica;

VIII - procedimentos específicos para prevenir fraudes e ilícitos no âmbito de processos licitatórios, na execução de contratos administrativos ou em qualquer interação com o setor público, ainda que intermediada por terceiros, tal como pagamento de tributos, sujeição a fiscalizações, ou obtenção de autorizações, licenças, permissões e certidões;

IX - independência, estrutura e autoridade da instância interna responsável pela aplicação do programa de integridade e fiscalização de seu cumprimento;

\footnotetext{
${ }^{13}$ BRASIL. Decreto ${ }^{\circ} 8.420$, de 18 de março de 2015. Regulamenta a Lei $n^{\circ} 12.846$, de $1^{\circ}$ de agosto de 2013, que dispõe sobre a responsabilização administrativa de pessoas jurídicas pela prática de atos contra a administração pública, nacional ou estrangeira e dá outras providências. Disponível em <http://www.planalto.gov.br/ccivil_03/_Ato2015-2018/2015/Decreto/D8420.htm> acesso em 25.01.2020.
} 
$X$ - canais de denúncia de irregularidades, abertos e amplamente divulgados a funcionários e terceiros, e de mecanismos destinados à proteção de denunciantes de boa-fé;

XI - medidas disciplinares em caso de violação do programa de integridade;

XII - procedimentos que assegurem a pronta interrupção de irregularidades ou infrações detectadas e a tempestiva remediação dos danos gerados;

XIII - diligências apropriadas para contratação e, conforme o caso, supervisão, de terceiros, tais como, fornecedores, prestadores de serviço, agentes intermediários e associados;

XIV - verificação, durante os processos de fusões, aquisições e reestruturações societárias, do cometimento de irregularidades ou ilícitos ou da existência de vulnerabilidades nas pessoas jurídicas envolvidas;

XV - monitoramento contínuo do programa de integridade visando seu aperfeiçoamento na prevenção, detecção e combate à ocorrência dos atos lesivos previstos no art. $5^{\circ}$ da Lei $n^{\circ} 12.846$, de 2013 ; e

XVI - transparência da pessoa jurídica quanto a doações para candidatos e partidos políticos.

Assim, as corporações, visando se aproveitar não somente dos benefícios da Lei como também visando evitar qualquer espécie de penalização ou risco, estas atuam internamente no sentido de estabelecer rigoroso sistema de controle contra ilegalidades e infrações ocorridas no seu âmbito. Outrossim, o compliance também trás outras vantagens ao âmbito empresarial como a manutenção da integridade da empresa, lealdade de seus funcionários, boas relações com seus stakeholders, clientes, fornecedores, investidores e reguladores, além de garantir uma boa reputação a empresa ${ }^{14}$.

Assim, a inúmeras vantagens para o estabelecimento de uma "delegacia” em funcionamento dentro da empresa, cuja função é detectar a existência de eventuais

14 MARTINS, José Alberto Monteiro e KNOERR Fernando Gustavo, THE POLICE POWER AND COMPLIANCE IN A LEGAL STATE AND THEIR INFLUENCE ON THE ANTI-CORRUPTION LAW (LAW 12,846 DATED AUGUST 1, 2013). Revista Jurídica Unicuritiba vol. 02, nº 43, Curitiba, 2016. pp.351-387 DOI: $10.6084 / \mathrm{m} 9$.figshare.3383485. Disponível

em

$<$ http://revista.unicuritiba.edu.br/index.php/RevJur/article/view/1836/1211> acesso em 25.01.2020.

Texto original: Compliance is a tool for risk management of a company, such as risk of legal or regulatory sanctions, financial loss, reputational losses arising from failure to comply with laws, regulations, codes of conduct, etc. There are many benefits in the use of compliance tools, such as integrity of the organization, employee loyalty, good reputation, good relations with stakeholders, suppliers, customers, investors and regulators. 
irregularidades, bem como amparar fundamentadamente, por meios documentais, o fato apurado $^{15}$.

Ou seja, tendo em vista que o Estado transferiu para o particular o estabelecimento de meios de identificar, apurar, investigar e, sobretudo, prevenir condutas irregulares.

Em outras palavras o Estado realiza uma transferência parcial do poder polícia para o particular.

Em linhas gerais, Meirelles ${ }^{16}$ esclarece que o poder de polícia é o mecanismo de frenagem de que tem administração pública contra os abusos do direito individual. Desse modo, a polícia, surge como "uma instituição criada e mantida pela Administração Pública, que dela se vale como instrumento para manter a ordem pública, a segurança dos cidadãos, bem comoa sua incolumidade em geral, aí incluída a vida, a honra, o patrimônio e outros bens jurídicos tutelados pelo Direito"17.

Ocorre que, essa transferência de poder pode ao mesmo tempo significar uma transferência de obrigações e deveres ao particular, dentre eles os respeitos as garantias do acusado.

\section{DAS GARANTIAS DO ACUSADO}

Conforme afirma Lenza, ao estudar Rui Barbosa, este últimodistinguiu "as disposições meramente declaratórias, que são as que imprimem existência legal aos direitos reconhecidos, e as disposições assecuratórias, que são as que, em defesa dos direitos, limitam o poder."18

Sobre os direitos fundamentais e as garantias, frisa Castro ${ }^{19}$ :

[...] o sentimento constitucional dos povos cultos desde logo percebeu que a nunciação solene de direitos fundamentais se revelaria insuficiente para a sua implementação

\footnotetext{
15 BERTONI, Felipe Faoro, Compliance e a privatização da investigação criminal. Canal Ciências Criminais. 17.11.2015. Disponível em $<$ https://canalcienciascriminais.com.br/compliance-e-a-privatizacao-da-investigacaocriminal/> extraído em 22.01.2020

${ }^{16}$ MEIRELLES, Hely Lopes; ALEIXO, Délcio Balestero; BURLE FILHO, José Emmanuel. Direito administrativo brasileiro. 36. Ed. São Paulo: Saraiva2012, p.138-140

${ }^{17}$ SOUZA, Sérgio Ricardo. Temas de direito processual penal constitucional aplicado. Impetus. 2006, p. 02

${ }^{18}$ LENZA, Pedro. Direito Constitucional Esquematizado. São Paulo: Saraiva. 2012, p.962

${ }^{19}$ CASTRO, Carlos Roberto Siqueira. A Constituição Aberta e os Direitos Fundamentais: Ensaios sobre o

Constitucionalismo Pós-Moderno e Comunitário. Rio de Janeiro: Forense, 2005.p. 727
} 
caso desacompanhada de correspondentes garantias instrumentais que os tornasse efetivos, sob o selo da coerção estatal, na hipótese de serem eles violados. Assim é que os autores das primeiras Constituições do nouveau régime na França pós revolucionária estabeleceram a distinção entre direitos do homem e suas garantias, a fim de complementar o sistema constitucional de proteção dos direitos da pessoa humana.

Ou seja, trata-se de um limite imposto ao poder coercitivo do Estado o qual visa garantir não somente os direitos individuais do ser humano, como ao mesmo tempo a própria estrutura democrática de governo.

Tais garantias se tornam especialmente vitais em face do poder punitivo do Estado, conforme afirmou William O. Douglas, Magistrado da Suprema Corte Norte Americana, em seu voto no caso Brady v. Maryland, que "a Sociedade vence não apenas quando os culpados são presos, mas também quando os julgamentos criminais são justos" ${ }^{20}$.

Dentre essas garantias estão o direito ao contraditório, o direito a não incriminação, direito ao devido processo legal, dentre outros ${ }^{21}$, além dos demais direitos e garantias fundamentais oponíveis por qualquer particular previsto no art. $5^{\circ}$ da Constituição.

\section{DA APLICAÇÃO DOS DIREITOS FUNDAMENTAIS NAS RELAÇÕES PRIVADAS}

Porém, são essas garantias aplicáveis as relações privadas? O direito constitucional contemporâneo tem reconhecido a expansão da eficácia dos direitos fundamentais às relações privadas. Essa tendência - produção de efeitos não exclusivamente verticais (do particular frente ao Estado), mas também horizontais (entre particulares) - revela-se plenamente compatível com a Carta Política brasileira ${ }^{22}$.

\footnotetext{
${ }^{20}$ UNITED STATES SUPREME COURT Brady v. Maryland, 373 U.S. 83 (1963)

${ }^{21}$ BRASIL. Constituição Federal. Art. $5^{\circ}$, inc. LIV, inc. LV, disponível em

$<$ http://www.planalto.gov.br/ccivil_03/constituicao/constituicao.htm> acesso 25.01.2020

${ }^{22}$ FIGUEIREDO, Fernanda Mendonça dos Santos. Direitos fundamentais aplicam-se a relações privadas. 2009. CONJUR. Disponível em <https://www.conjur.com.br/2009-fev-05/stf-reconhece-aplicacao-direta-direitosfundamentais-relacoes-privadas $>$ acesso em 26.01.2020
} 
O Supremo Tribunal Federal analisou questão atinente à eficácia dos direitos fundamentais nas relações privadas proferindo decisão por ocasião do julgamento do Recurso Extraordinário $201.819 / \mathrm{RJ}^{23}$, cuja ementa é transcrita abaixo:

EMENTA: SOCIEDADE CIVIL SEM FINS LUCRATIVOS. UNIÃO BRASILEIRA DE COMPOSITORES. EXCLUSÃO DE SÓCIO SEM GARANTIA DA AMPLA DEFESA E DO CONTRADITÓRIO. EFICÁCIA DOS DIREITOS FUNDAMENTAIS NAS RELAÇÕES PRIVADAS. RECURSO DESPROVIDO. I. EFICÁCIA DOS DIREITOS FUNDAMENTAIS NAS RELAÇÕES PRIVADAS. As violações a direitos fundamentais não ocorrem somente no âmbito das relações entre o cidadão e o Estado, mas igualmente nas relações travadas entre pessoas físicas e jurídicas de direito privado. Assim, os direitos fundamentais assegurados pela Constituição vinculam diretamente não apenas os poderes públicos, estando direcionados também à proteção dos particulares em face dos poderes privados. II. OS PRINCÍPIOS CONSTITUCIONAIS COMO LIMITES À AUTONOMIA PRIVADA DAS ASSOCIAÇÕES. A ordem jurídico-constitucional brasileira não conferiu a qualquer associação civil a possibilidade de agir à revelia dos princípios inscritosnas leis e, em especial, dos postulados que têm por fundamento direto o próprio texto da Constituição da República, notadamente em tema de proteção às liberdades e garantias fundamentais. $\mathrm{O}$ espaço de autonomia privada garantido pela Constituição às associações não está imune à incidência dos princípios constitucionais que asseguram o respeito aos direitos fundamentais de seus associados. A autonomia privada, que encontra claras limitações de ordem jurídica, não pode ser exercida em detrimento ou com desrespeito aos direitos e garantias de terceiros, especialmente aqueles positivados em sede constitucional, pois a autonomia da vontade nãoconfere aos particulares, no domínio de sua incidência e atuação, o poder de transgredir ou de ignorar as restrições postas e definidas pela própria Constituição, cuja eficácia e força normativa também se impõem, aos particulares, no âmbito de suas relações privadas, em tema de liberdades fundamentais. III. SOCIEDADE CIVIL SEM FINS LUCRATIVOS. ENTIDADE QUE INTEGRA ESPAÇO PÚBLICO, AINDA QUE NÃO-ESTATAL. ATIVIDADE DE CARÁTER PÚBLICO. EXCLUSÃO DE SÓCIO SEM GARANTIA DO DEVIDO PROCESSO LEGAL.APLICAÇÃO DIRETA DOS DIREITOS FUNDAMENTAIS À AMPLA DEFESA E AO CONTRADITÓRIO. As associações privadas que exercem função predominante em

\footnotetext{
${ }^{23}$ STF. RE 201.819/RJ, rel. min. Ellen Gracie, rel. p/ acórdão min. Gilmar Mendes, DJ 27/10/2006.
} 
determinado âmbito econômico e/ou social, mantendo seus associados em relações de dependência econômica e/ou social, integram o que se pode denominar de espaço público, ainda que não-estatal. A União Brasileira de Compositores - UBC, sociedade civil sem fins lucrativos, integra a estrutura do ECAD e, portanto, assume posição privilegiada para determinar a extensão do gozo e fruição dos direitos autorais de seus associados. A exclusão de sócio do quadro social da UBC, sem qualquer garantia de ampla defesa, do contraditório, ou do devido processo constitucional, onera consideravelmente o recorrido, o qual fica impossibilitado de perceber os direitos autorais relativos à execução de suas obras. A vedação das garantias constitucionais do devido processo legal acaba por restringir a própria liberdade de exercício profissional do sócio. O caráter público da atividade exercida pela sociedade e a dependência do vínculo associativo para o exercício profissional de seus sócios legitimam, no caso concreto, a aplicação direta dos direitos fundamentais concernentes ao devido processo legal, ao contraditório e à ampla defesa (art. $5^{\circ}$, LIV e LV, CF/88). IV. RECURSO EXTRAORDINÁRIO DESPROVIDO. (RE 201819, Relator(a): Min. ELLEN GRACIE, Relator(a) p/ Acórdão: Min. GILMAR MENDES, Segunda Turma, julgado em 11/10/2005, DJ 27-10-2006 PP-00064 EMENT VOL-02253-04 PP-00577 RTJ VOL-00209-02 PP-00821)

A controvérsia dos autos tratava da exclusão de sócio dos quadros da União Brasileira de Compositores, sociedade civil sem fins lucrativos dotada de personalidade jurídica de direito privado. Segundo é informado pelo relatório do acórdão, na forma do estatuto da associação, deveria ser criada uma comissão para apurar os indícios, atos e fatos que eventualmente ensejariam a punição de sócio que houvesse contrariado os deveres estatutários. Contudo, embora tivesse designado uma comissão especial para a apuração das irregularidades, a deliberação por excluir o compositor fora tomada sem antes lhe oportunizar a chance de rebater as acusações e produzir provas em seu favor.

O afastamento do compositor foi revertido pelo Tribunal de Justiça do Rio de Janeiro ao argumento de que ocorrera em violação ao direito à ampla defesa e ao contraditório previsto no artigo $5^{\circ}$, inciso LV da Constituição Federal de $1988^{24}$. A União Brasileira de Compositores

\footnotetext{
${ }^{24}$ BRASIL. Constituição Federal. Art. $5^{\circ}$ Todos são iguais perante a lei, sem distinção de qualquer natureza, garantindo-se aos brasileiros e aos estrangeiros residentes no País a inviolabilidade do direito à vida, à liberdade, à igualdade, à segurança e à propriedade, nos termos seguintes (...): LV - aos litigantes, em processo judicial ou administrativo, e aos acusados em geral são assegurados o contraditório e ampla defesa, com os meios e recursos
} 
defendeu que o princípio constitucional seria inaplicável ao caso por não pertencer à administração pública. Sendo de direito privado, seu relacionamento societário seria regulado pelos estatutos e atos regimentais particulares.

A divergência entre os membros da $2^{\text {a }}$ Turma do Supremo Tribunal Federal, cuja apertada maioria votou pelo desprovimento do recurso, refletiu as divergências sobre os efeitos práticos da alteração de orientação e pensamento motivada pelo surgimento do Welfare State. O paradigma liberal circunscrevia o texto constitucional às relações travadas no âmbito do Estado, entre seus órgãos ou entre ele e os particulares. Nas relações privadas, cabia ao Estado o papel de garantir as liberdades individuais dos cidadãos, velando pela observância dos princípios da legalidade e da igualdade formal.

A posição constitucional clássica define os direitos fundamentais como direitos subjetivos de defesa dos indivíduos exercidos contra o poder do Estado. Desta forma, incabível seria a evocação dos direitos fundamentais para a solução de um conflito entre particulares ${ }^{25}$. Essa posição foi sustentada pela ministra Ellen Gracie, então relatora, acompanhada pelo ministro Carlos Velloso, os quais deram provimento ao recurso sob a alegação de que as associações privadas possuem autonomia para elaboração de suas regras e, neste compasso, os indivíduos que nela ingressariam tinham de aderir a estas normas, ademais em se considerando o cumprimento do estatuto, não haveria se falar em anulação da exclusão do associado ${ }^{26}$.

Porém, essa posição foi vencida pelo posicionamento ministro Gilmar Mendes, seguido pelos ministros Joaquim Barbosa e Celso de Mello, fundamentando sua decisão na teoria da aplicabilidade imediata dos direitos fundamentais às relações privadas ${ }^{27}$.

Consoante ao voto-vista do ministro Gilmar Mendes:

"o entendimento segundo o qual os direitos fundamentais atuam de forma unilateral na relação entre o cidadão e o Estado acaba por legitimar a ideia de que haveria para o cidadão sempre um espaço livre de qualquer ingerência estatal".

a ela inerentes. Disponível em <http://www.planalto.gov.br/ccivil_03/constituicao/constituicao.htm> acesso 25.01.2020

${ }^{25}$ FIGUEIREDO, Fernanda Mendonça dos Santos. Direitos fundamentais aplicam-se a relações privadas. 2009. CONJUR. Disponível em <https://www.conjur.com.br/2009-fev-05/stf-reconhece-aplicacao-direta-direitosfundamentais-relacoes-privadas $>$ acesso em 26.01.2020

${ }^{26}$ STF. RE 201.819/RJ, rel. min. Ellen Gracie, rel. p/ acórdão min. Gilmar Mendes, DJ 27/10/2006.

${ }^{27}$ SARMENTO, DANIEL. Direitos Fundamentais e Relações Privadas. Rio De Janeiro: Lumen Juris, 2004 
A seu ver, os direitos privados remeteriam a um direito fundamental que não poderia ser tolhido pela mera presunção da igualdade horizontal entre particulares.

$\mathrm{Na}$ fundamentação do voto, o ministro Gilmar Mendes valeu-se da jurisprudência e do Direito Comparado - em especial da Alemanha e de Portugal. A Lei Fundamental de Bonn ${ }^{28}$, a qual preconiza a aplicação direta dos direitos fundamentais na área privatista, aofundamento de que os atos jurídicos não devem contrariar a ordem pública. Outrossim o ministro também afirmou que a jurisprudência do Supremo já contemplava a incidência direta dos direitos fundamentais na esfera privada, como no RE 158.215/RS ${ }^{29}$, em que determinou a observância do direito e a ampla defesa na exclusão de associado de cooperativa, e no RE 161.243/DF ${ }^{30}$, em que aplicou a empregado brasileiro o estatuto de uma empresa que previa benefícios a empregados de nacionalidade francesa.

Esse entendimento acerca da aplicabilidade dos direitos fundamentais às relações privadas foi sedimentado recentemente na decisão do STF no Agravo Regimental no Recurso Extraordinário com Agravo 1.008.625/SP ${ }^{31}$. De acordo com o relator, ministro Luiz Fux, seguido por unanimidade na $1^{\text {a }}$ Turma, "as normas definidoras de direitos e garantias fundamentais têm campo de incidência em qualquer relação jurídica, seja ela pública, mista ou privada, donde os direitos fundamentais assegurados pela Carta Política vinculam não apenas os poderes públicos, alcançando também as relações privadas”.

Portanto, se baseando no entendimento jurisprudencial do STF, está claro que os procedimentos de investigação interna, e os procedimentos de compliance devem respeitar os direitos fundamentais.

Especialmente quando considerarmos que o compliance nada mais é, como anteriormente exposto, a transferência do poder de policia do Estado ao particular.

Utilizando novamente o Direito Comparado, em Marsh v. Alabama, a Suprema Corte Norte Americana decidiu que, ao julgar um caso acerca de liberdade de expressão em uma

\footnotetext{
${ }^{28}$ BRASIL. DISCURSO PROFERIDO EM 25.5.2009 NA EMBAIXADA DA REPÚBLICA FEDERAL DA ALEMANHA POR OCASIÃO DOS 60 ANOS DA LEI FUNDAMENTAL DE BONN. Disponível em $<$ http://www.stf.jus.br/arquivo/cms/noticiaArtigoDiscurso/anexo/discAlemanha.pdf $>$ acesso em 25.01.2020

${ }^{29}$ STF. RE 158.215/RS, rel. min. Marco Aurélio, DJ 7/6/1996.

${ }^{30}$ STF. RE 161.243/DF, rel. min. Carlos Velloso, DJ 19/12/1997.

${ }^{31}$ STF. AgRg no ARE 1.008.25, rel. min. Luiz Fux, DJe 19/4/2017
} 
cidade de propriedade de uma empresa, quanto mais o dono da propriedade privada, no caso em questão um imóvel, abre a mesma ao público, mais ele aceita a interferência dos direitos fundamentais de terceiros nas relações desenvolvidas em torno de sua propriedade ${ }^{32}$.

Assim tendo em vista o poder de policia se tratar de poder notoriamente associado a atividade estatal, está clara a incidência dos direitos e garantias fundamentais sobre os processos de compliance.

\subsection{EXEMPLOS DA APLICAÇÂO DOS DIREITOS FUNDAMENTAIS EM PROCEDIMENTOS DE COMPLIANCE}

Um dos exemplos que podemos citar acerca da interferência dos direitos e garantias fundamentais nas relações oriundas do compliance, é o da exigência do artigo 42, XIII, do Decreto $8.420 / 15^{33}$, acerca das diligências apropriadas para contratação e, conforme o caso, supervisão, de terceiros, tais como, fornecedores, prestadores de serviço, agentes intermediários e associados.

Em março de 2015, o TST acolheu a proposta de Incidente de recurso de revista repetitivo nos processos RR-243000-58.2013.5.13.0023 referente ao tema "Dano moral. Exigência de certidão negativa de antecedentes criminais"34.

No julgamento, o TST firmou a tese de que a exigência de antecedentes criminais que venha a configurar tratamento discriminatório do trabalhador ou que não se justifica em razão de previsão em lei, natureza do ofício ou do grau especial de fidúcia existente na relação de emprego configura dano moral, que será devido independentemente se o trabalhador foi ou não contratado pela empresa.

\footnotetext{
32 UNITED STATES SUPREME COURT. Marsh v. Alabama, 326 U.S. 501 (1946)

${ }^{33}$ BRASIL. Decreto $n^{\circ} 8.420$, de 18 de março de 2015. Regulamenta a Lei $n^{\circ} 12.846$, de $1^{\circ}$ de agosto de 2013, que dispõe sobre a responsabilização administrativa de pessoas jurídicas pela prática de atos contra a administração pública, nacional ou estrangeira e dá outras providências. Disponível em

$<$ http://www.planalto.gov.br/ccivil_03/_Ato2015-2018/2015/Decreto/D8420.htm> acesso em 25.01.2020.

${ }^{34}$ TST. IRR-RR-243000-58.2013.5.13.0023, Subseção I Especializada em Dissídios Individuais, Redator Ministro João Oreste Dalazen, DEJT 22/09/2017
} 
Por outro lado, se existir previsão legal, se assim demandar a natureza do ofício ou o grau especial de fidúcia, é possível que o empregador exija a certidão de antecedentes criminais. Consoante a ementa do recurso:

"INCIDENTE DE RECURSO DE REVISTA REPETITIVO. TEMA Nº 0001. DANO
MORAL. EXIGÊNCIA DE CERTIDÃO DE ANTECEDENTES CRIMINAIS. CANDIDATO A EMPREGO 1 . Não é legítima e caracteriza lesão moral a exigência de Certidão de Antecedentes Criminais de candidato a emprego quando traduzir tratamento discriminatório ou não se justificar em razão de previsão em lei, da natureza do ofício ou do grau especial de fidúcia exigido. 2 . A exigência de Certidão de Antecedentes Criminais de candidato a emprego é legítima e não caracteriza lesão moral quando amparada em expressa previsão legal ou justificar-se em razão da natureza do ofício ou do grau especial de fidúcia exigido, a exemplo de empregados domésticos, cuidadores de menores, idosos ou deficientes (em creches, asilos ou instituições afins), motoristas rodoviários de carga, empregados que laboram no setor da agroindústria no manejo de ferramentas de trabalho perfurocortantes, bancários e afins, trabalhadores que atuam com substâncias tóxicas, entorpecentes e armas, trabalhadores que atuam com informações sigilosas. 3 . A exigência de Certidão de Antecedentes Criminais, quando ausente alguma das justificativas supra, caracteriza dano moral in re ipsa , passível de indenização, independentemente de o candidato ao emprego ter ou não sido admitido"35

Quantos aos demais direitos, é primeiro importante ressaltar que em toda relação de emprego existe um poder diretivo do empregador, que faz com que as diretrizes estabelecidas pela empresa sejam seguidas pelo empregado. Como observou Vecchi ${ }^{36}$ :

“[...] a relação de emprego é a relação jurídica obrigacional vista como um processo, nascida do contrato (em sentido não tradicional), travada e desenvolvida entre empregado e empregador. Nesta relação, o empregado (pessoa física) presta ou se obriga a prestar serviços de natureza não eventual, pessoal, com intuito de

\footnotetext{
${ }^{35}$ TST. IRR-RR-243000-58.2013.5.13.0023, Subseção I Especializada em Dissídios Individuais, Redator Ministro João Oreste Dalazen, DEJT 22/09/2017

${ }^{36}$ VECCHI, I.D. Direito material do trabalho: noções introdutórias, relação de emprego e contrato de trabalho. Curitiba: Juruá, 2016.
} 
remuneração e subordinada (sob dependência) ao empregador (pessoa física, jurídica ou entes despersonalizados), o que dirige a prestação dos serviços ou a obrigação de prestar os serviços e o remunera em virtude do trabalho feito e, em certas circunstâncias, pela simples obrigação de prestar trabalho.”

Assim em virtude dessa subordinação, é reconhecido o direito de fiscalizar do empregador, o que, por mais que seja reconhecido a interferência dos direitos fundamentais nas relações privadas estes não são aplicados da mesma exata forma como se em face do Estado fosse.

Por exemplo, é reconhecido constitucionalmente o direito e garantia a privacidade e inviolabilidade telefônica e telemática, a qual inclusive necessita de uma ordem judicial para autorizar sua quebra, em face de uma investigação organizada pelo Estado ${ }^{37}$.

Conforme o artigo 5 $5^{\circ}$ XII, da Constituição Federal, é inviolável o sigilo da correspondência e das comunicações telegráficas, de dados e das comunicações telefônicas, salvo, no último caso, por ordem judicial, nas hipóteses e na forma que a lei estabelecer para fins de investigação criminal ou instrução processual penal ${ }^{38}$.

Este dispositivo constitucional vem ser regulado pela Lei $n^{\circ} 9.296 / 96$, a qual define os limites, forma e possibilidades da quebra de sigilo telefônico ${ }^{39}$.

Inclusive, a jurisprudência trata o presente instrumento como uma medida extremamente invasiva, sendo imperioso a demonstração de necessidade da mesma sob pena de nulidade. Neste sentido:

PENAL. HABEAS CORPUS. FORMAÇÃO DE QUADRILHA. CRIME CONTRA A ORDEM TRIBUTÁRIA. FRAUDE EM LICITAÇÕES. PRÉVIO MANDAMUS DENEGADO. PRESENTE WRIT SUBSTITUTIVO DE RECURSO ORDINÁRIO. INVIABILIDADE. VIA INADEQUADA. INTERCEPTAÇÃO TELEFÔNICA.

\footnotetext{
${ }^{37}$ Ver BRASIL. Constituição Federal. Art. $5^{\circ}$ [...] XII - é inviolável o sigilo da correspondência e das comunicações telegráficas, de dados e das comunicações telefônicas, salvo, no último caso, por ordem judicial, nas hipóteses e na forma que a lei estabelecer para fins de investigação criminal ou instrução processual penal. Disponível em $<$ http://www.planalto.gov.br/ccivil_03/constituicao/constituicao.htm> acesso em 27.01.2020

38 Ver BRASIL. $\quad$ Constituição Federal. Art. $\quad 5^{\circ}$,XII. Disponível em $<$ http://www.planalto.gov.br/ccivil_03/constituicao/constituicao.htm> acesso em 27.01.2020

${ }^{39}$ BRASIL. Lei ${ }^{\circ}$ 9.296, de 24 de julho de 1996. Regulamenta o inciso XII, parte final, do art. $5^{\circ}$ da Constituição Federal. Disponível em <http://www.planalto.gov.br/ccivil_03/leis/19296.htm> acesso em 25.01.2020
} 
INDEVIDO ACESSO DO MATERIAL OBTIDO. SIMILITUDE DE OFÍCIOS DE UMA DADA OPERADORA DE TELEFONIA COM OUTROS DECLARADOS ILEGAIS EM FEITO DIVERSO. ANÁLISE FÁTICO-PROBATÓRIA. IMPOSSIBILIDADE. AUSÊNCIA DE DOCUMENTAÇÃO COMPROBATÓRIA NOS AUTOS. NULIDADE DO MONITORAMENTO TELEFÔNICO. DEMONSTRAÇÃO DA IMPRESCINDIBILIDADE DA MEDIDA EXTREMA. CARÊNCIA. DECISÃO DEFERITÓRIA PRIMEVA. MOTIVAÇÃO ABSTRATA. PRORROGAÇÕES. FUNDAMENTAÇÃO INIDÔNEA. ELEMENTOS DOS AUTOS A REFUTAR A MANTENÇA DA MEDIDA. FLAGRANTE ILEGALIDADE. EXISTÊNCIA. HABEAS CORPUS NÃO CONHECIDO. ORDEM CONCEDIDA DE OFÍCIO. 1. É imperiosa a necessidade de racionalização do emprego do habeas corpus, em prestígio ao âmbito de cognição da garantia constitucional e em louvor à lógica do sistema recursal. In casu, foi impetrada indevidamente a ordem como substitutiva de recurso ordinário. 2. Tanto a alegação de indevido acesso ao material do monitoramento quanto eventual similitude do teor dos ofícios de uma dada operadora de telefonia - cuja ilegalidade foi constatada em ofícios outros exarados em feito diverso - demandam revolvimento fático- probatório, não condizente com a angusta via do writ, em especial diante do expurgo pelo Tribunal estadual de qualquer interferência dos termos do julgamento do outro mandamus na situação vertida nestes autos. 3. Ademais, a aferição do alegado constrangimento ilegal sofrido no que pertine ao acesso do teor das interceptações, fora do âmbito restrito do procedimento investigatório e/ou processo penal, é obstaculizada em virtude da inexistência nos autos de documentação comprobatória suficiente. 4. Na hipótese em apreço, constata-se a existência de flagrante ilegalidade, pois, para o desencadeamento de medida cautelar extrema, como a quebra do sigilo telefônico, deve-se esmiuçar a sua imprescindibilidade, de modo a pormenorizar a assertiva de não dispor de procedimentos investigatórios outros, menos invasivos, para a obtenção de provas aptas a robustecer eventual imputação delitiva. 5. A decretação da medida cautelar de interceptação não atendeu aos pressupostos e fundamentos de cautelaridade, visto que, não obstante os crimes investigados serem punidos com reclusão e haver investigação formalmente instaurada, descurou-se da demonstração da necessidade da medida extrema e da dificuldade para a sua apuração por outros meios, carecendo, portanto, do fumus comissi delicti e do periculum in mora. 6. A mera transcrição dos termos legais no decisum que defere a constrição não satisfaz a indispensável fundamentação acerca da necessidade da providência, que quebranta a regra do sigilo. 7. As autorizações subsequentes de interceptações 
telefônicas, bem como suas prorrogações, não primaram por salientar elementos dos autos que porventura embasá-las-ia, evidenciando-se, assim, a prescindibilidade da medida, apurando-se irregularidade na manutenção da constrição no período. 8 . Habeas corpus não conhecido. Ordem concedida, de ofício, a fim de declarar nula a evidência resultante da interceptação telefônica ocorrida nos autos do Processo n. ${ }^{\circ}$ 0009997-05.2013.8.26.0114, Controle n. ${ }^{\text {o } 307 / 2013, ~ d a ~} 1^{\text {a }}$ Vara Criminal da Comarca de Campinas/SP, determinando que seja envelopado, lacrado e entregue aos acusados o material resultante da medida de monitoramento. ${ }^{40}$

No entanto, quando se trata do âmbito laboral, o TST mantém a posição de que o uso do e-mail da empresa, quando desautorizado pelo empregador, implica em indisciplina por parte do trabalhador, sendo possível por parte do Empregador a sua supervisão e fiscalização. O entendimento do Ministro do TST João Orestes Dalazen sobre a questão foi o seguinte, conforme descrito por $\mathrm{Schio}^{41}$ :

Entendimento do Ministro do TST João Orestes Dalazen sobre o uso de e-mail da empresa para fins pessoais

“1. Os sacrossantos direitos do cidadão à privacidade e ao sigilo de correspondência, constitucionalmente assegurados, concernem à comunicação estritamente pessoal, ainda que virtual ('e-mail particular'). Assim, apenas o e-mail pessoal ou particular do empregado, socorrendo-se de provedor próprio, desfruta de proteção constitucional e legal de inviolabilidade.

2. Solução diversa impõe-se em se tratando do chamado 'e-mail' corporativo, instrumento de comunicação virtual mediante o qual o empregado louva-se de terminal de computador e de provedor da empresa, bem assim do próprio endereço eletrônico que lhe é disponibilizado igualmente pela empresa. Destina-se este a que nele trafeguem mensagens de cunho estritamente profissional. Em princípio, é de uso corporativo, salvo consentimento do empregador. Ostenta, pois, natureza jurídica equivalente à de uma ferramenta de trabalho proporcionada pelo empregador ao empregado para a consecução do serviço."

\footnotetext{
${ }^{40}$ STJ. HC 251.540/SP, Rel. Ministra MARIA THEREZA DE ASSIS MOURA, SEXTA TURMA, julgado em 05/08/2014, DJe 18/08/2014

${ }^{41}$ SCHIO, A.C.S. Cyberslacking: do direito à privacidade ao poder de fiscalizar. In: VILLATORE, M.A.C.; HASSON, R. (coord.). Estado \& atividade econômica: o direito laboral em perspectiva. Curitiba: Juruá, 2010.
} 
Nesse caso, o entendimento jurisprudencial do TST e da Justiça do Trabalho como um todo é de que a fiscalização das mensagens realizadas pelos empregados durante o horário de trabalho, utilizando aparatos tecnológicos fornecidos pela empresa, não fere o direito à intimidade do empregado:

"DANOS MORAIS. INDENIZAÇÃO. COMUNICAÇÃO ELETRÔNICA. ACESSO AO CONTEÚDO DAS MENSAGENS ENVIADAS VIA SKYPE. Apesar de o Skype se tratar de ferramenta de comunicação acessível ao público em geral, quando destinada pelo empregador como ferramenta de trabalho, equipara-se à ferramenta corporativa. Portanto, não ofende o direito à intimidade, tampouco viola $\mathrm{o}$ sigilo da correspondência, o acesso pelo empregador ao conteúdo das mensagens trocadas pelos seus empregados em computadores da empresa, durante o expediente de trabalho, mormente quando cientificados os trabalhadores dessa possibilidade". ${ }^{2}$

Assim, o empregador, desde que dentro dos limites do estipulado contratualmente, e garantindo os demais direitos tem mais flexibilidade que o Estado em suas investigações. De fato, trata-se de um verdadeiro jogo de equilíbrio no qual o empregador não pode suprimir os direitos de seus funcionários, porém a ele é permitido diversos poderes de fiscalização, os quais facilitam a função de compliance.

Ou seja, desde que permitido pela Lei, e que o empregador, e que este tenha seus direitos preservados, como por exemplo no caso da jurisprudência acima, a notificação dos mesmos acerca dessa possibilidade.

No entanto, caso esses direitos não sejam respeitados, é possível inclusive a decretação da nulidade da prova adquirida por esse procedimento interno.

\section{CONSIDERAÇÕES FINAIS}

Consoante ao entendimento do STF já demonstrado anteriormente, as violações a direitos fundamentais não ocorrem somente no âmbito das relações entre o cidadão e oEstado,

\footnotetext{
42 TRT-12 - RO: 00007023820145120052 SC 0000702-38.2014.5.12.0052, Relator: GISELE PEREIRA ALEXANDRINO, SECRETARIA DA 3A TURMA, Data de Publicação: 11/09/2015.
} 
mas igualmente nas relações travadas entre pessoas físicas e jurídicas de direito privado. Assim, os direitos fundamentais assegurados pela Constituição vinculam diretamente não apenas os poderes públicos, estando direcionados também à proteção dos particulares em face dos poderes privados.

E dessas relações não está excluído os poderes de polícia atribuídos as empresas nos procedimentos de compliance.

Essa transferência de poder inclusive apenas solidifica o necessário, uma vez que se trata de poder eminentemente público.

Dessa forma, para cumprir efetivamente o esperado e incentivado pela Lei, os programas de compliance das empresas devem levar em conta os direitos e garantias fundamentais de seus funcionários. Ocorre que, os níveis de exigência do particular são muito inferiores ao do Estado, especialmente quando o caso se trata do poder de controle e subordinação.

Mesmo assim, em nada altera a conclusão de que os direitos fundamentais se encontram presentes, devendo a violação destes ser vedada para permitir, dentro do razoável, a consecução e verdadeira efetividade dos programas de integridade.

\section{REFÊNCIAS}

BERTONI, Felipe Faoro, Compliance e a privatização da investigação criminal. Canal Ciências Criminais. 17.11.2015. Disponível em $<$ https://canalcienciascriminais.com.br/compliance-e-a-privatizacao-da-investigacao- criminal/> extraído em 22.01.2020.

BRASIL. Constituição Federal. Art. 5o, inc. LIV, inc. LV, disponível em $\leq$ http://www.planalto.gov.br/ccivil 03/constituicao/constituicao.htm>acesso 25.01.2020.

BRASIL. Decreto $\mathbf{n}^{\mathbf{0}} \mathbf{8 . 4 2 0}$, de 18 de março de 2015. Regulamenta a Lei $\mathrm{n}^{\circ} 12.846$, de $1^{\circ}$ de agosto de 2013, que dispõe sobre a responsabilização administrativa de pessoas jurídicas pela prática de atos contra a administração pública, nacional ou estrangeira e dá outras providências. Disponível em $\leq \mathrm{http}: / /$ www.planalto.gov.br/ccivil 03/ Ato2015-

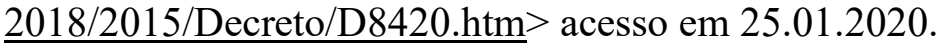

BRASIL. Lei $\mathbf{n}^{0}$ 12.846, de $1^{0}$ de agosto de 2013. Dispõe sobre a responsabilização administrativa e civil de pessoas jurídicas pela prática de atos contra a administração pública, nacional ou estrangeira, e dá outras providências. Disponível em $<$ http://www.planalto.gov.br/ccivil 03/_Ato2011-2014/2013/Lei/L12846.htm $>$ acesso em 24.01 .2020 . 
CASTRO, Carlos Roberto Siqueira. A Constituição Aberta e os Direitos Fundamentais: Ensaios sobre o Constitucionalismo Pós-Moderno e Comunitário. Rio de Janeiro: Forense, 2005.

CVM Recomendações Da CVM Sobre Governança Corporativa. Disponível em $\leq$ http://www.cvm.gov.br/export/sites/cvm/decisoes/anexos/0001/3935.pdf $>$ acesso em 23.01.2020.

FIGUEIREDO, Fernanda Mendonça dos Santos. Direitos fundamentais aplicam-se a relações privadas. 2009. CONJUR. Disponível em $<$ https://www.conjur.com.br/2009-fev-05/stfreconhece-aplicacao-direta-direitos- fundamentais-relacoes-privadas $>$ acesso em 26.01.2020.

GUYNN Randall D. The Financial Panic of 2008 and Financial Regulatory Reform. Harvard Law School Forum on Corporate Governance. Disponível em $<$ https://corpgov.law.harvard.edu/2010/11/20/the-financial-panic-of-2008-and-financialregulatory-reform/> acesso em 22.01.2020.

LENZA, Pedro. Direito Constitucional Esquematizado. São Paulo: Saraiva. 2012.

MARTINS, José Alberto Monteiro e KNOERR, Fernando Gustavo. The police power and compliance in a legal state and their influence on the anti-corruption law (law 12,846 dated august 1, 2013). Revista Jurídica Unicuritiba vol. 02, $\mathrm{n}^{\circ}$. 43, Curitiba, 2016. pp.351-387 DOI:

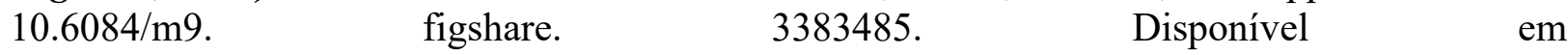
$\leq$ http://revista.unicuritiba.edu.br/index.php/RevJur/article/view/1836/1211 $>\quad$ acesso em 25.01.2020.

MEIRELLES, Hely Lopes; ALEIXO, Délcio Balestero; BURLE FILHO, José Emmanuel. Direito administrativo brasileiro. 36. Ed. São Paulo: Saraiva, 2012.

POLICÍA FEDERAL DO BRASIL. Operação Lava Jato Números. Disponível em $<$ http://www.pf.gov.br/imprensa/lava-jato/numeros-da-operacao-lava-jato $>$ acesso em 19.12.2020.

REINO UNIDO. Bribery Act. 2010. Disponível em $<$ http://www.legislation.gov.uk/ukpga/2010/23/contents $>$ acesso em 24.01.2020.

SARMENTO, DANIEL. Direitos Fundamentais e Relações Privadas. Rio De Janeiro: Lumen Juris, 2004.

SCHIO, A.C.S. Cyberslacking: do direito à privacidade ao poder de fiscalizar. In: VILLATORE, M.A.C.; HASSON, R. (coord.). Estado \& atividade econômica: o direito laboral em perspectiva. Curitiba: Juruá, 2010.

SOUZA, Sérgio Ricardo. Temas de direito processual penal constitucional aplicado. Impetus. 2006.

SUBRAMANIAN, Guhan. Corporate Governance 2.0. Havard Business Review. 2015. Disponível em $\leq \mathrm{https}: / /$ hbr.org/2015/03/corporate-governance-2-0 $>$. Acesso em 22.01.2020.

UNITED STATES SUPREME COURT Brady v. Maryland, 373 U.S. 83 (1963). 
VECCHI, I.D. Direito material do trabalho: noções introdutórias, relação de emprego e contrato de trabalho. Curitiba: Juruá, 2016.

ZINI, Júlio César Faria. Apontamentos sobre o direito penal econômico e suas especificidades, Rev. Fac. Direito UFMG, Belo Horizonte, n. 60, p. 147 a 207, jan./jun. 2012. Disponível em $\leq$ https://www.direito.ufmg.br/revista/index.php/revista/article/download/P.03042340.2012v60p147/165>. Acesso em 22.01.2020. 